\title{
A Study on Calculation Theory and Method of Transverse Distribution Coefficient of the Corrugated Steel Web Box Girder Based on the "Modified Rigid Jointed Beam Method"
}

(China Tower Limited by Share Ltd Guang'an branch, Guang'an City, Sichuan, 63800, China )

\section{The Mechanical Model of the Modified Rigid Jointed Beam Method}

This paper selects the single-box five-chamber cross section corrugated steel web box girder bridge as the research object to deduce the "modified rigid jointed beam method" of the single-box multi-chamber corrugated steel box girder bridge. For the application of the rigid-connected beam method for the single-box multiple-chamber corrugated steel web box girder, the essential of the modification is to supplement the redundants at the cut to achieve the purpose of restoring the actual force condition of the structure ${ }^{[1]}$. The box girders are cut along the top and bottom boards of the web. Each chamber has two cuts. For the "traditional rigid jointed beam method", the single-box multi-chamber corrugated steel web box girder is equivalent to a flat plate beam model, and only the vertical shear at the cut at and the transverse bending moment, other than the transverse force, are considered. In the single-box multi-chamber corrugated steel web box girder, the longitudinal shear force is further study. method of the transverse load distribution of the steel box girder bridge need further study.Based on the "traditional rigid jointed process and the programming ideas of the transverse distribution coefficient of corrugated steel web composite box girder of the "modified rigid jointed beam method".beam method" and the existing research, this paper proposes the "modified rigid-jointed beam method" in combination with the specific internal force distribution of corrugated steel web composite box girder. The computational scheme and formula of mechanics, the calculation process and the programming ideas of the transverse distribution coefficient of corrugated steel web composite box girder of the "modified rigid jointed beam method".

also ignored ${ }^{[2]}$. The mechanical properties of the single-box multi-chamber corrugated steel web box girder indicate that the top and bottom boards and the webs of the box girder are subjected to shear flow under the eccentric load. After thebox girder is cut, the transverse force of the

\begin{abstract}
The PC box girder Bridge with corrugated steel web, as a new kind of bridge structure, has different mechanical properties from that of the ordinary concrete box girder bridge. Due to the late development of the corrugated steel web pre-stressed box girder structure, the domestic experts have made little research on the transverse load distribution of PC box Girder Bridge with corrugated steel webs. Whether the method of calculating the transverse distribution coefficient in the classical box girder theory can be applied to the corrugated steel web composite box girder and how to further improve the calculation theory and method of the transverse load distribution of the steel box girder bridge need
\end{abstract}

Key words:Corrugated steel web composite box girder; Transverse distribution coefficient; Traditional rigid jointed beam method; Modified rigid jointed beam method; Mechanical model

Published on 30th Sept,2017 
redundants of the top and bottom boards cannot be ignored due to the existence of the shear flow. In addition, the load is generally applied to the top board of the box girder. Thus, for the redundants, the transverse bending moment is on the top board, and that on the bottom board is relatively small and can be ignored. In summary, the redundants at the cut of the single-box multi-chamber corrugated steel web box girder bridge according to the "modified rigid jointed beam method", the top board bears combination of the vertical sheer, transverse bending moment and transverse force, the bottom board bears the vertical shear and transverse force, with the mechanical diagram shown in Figure 1.

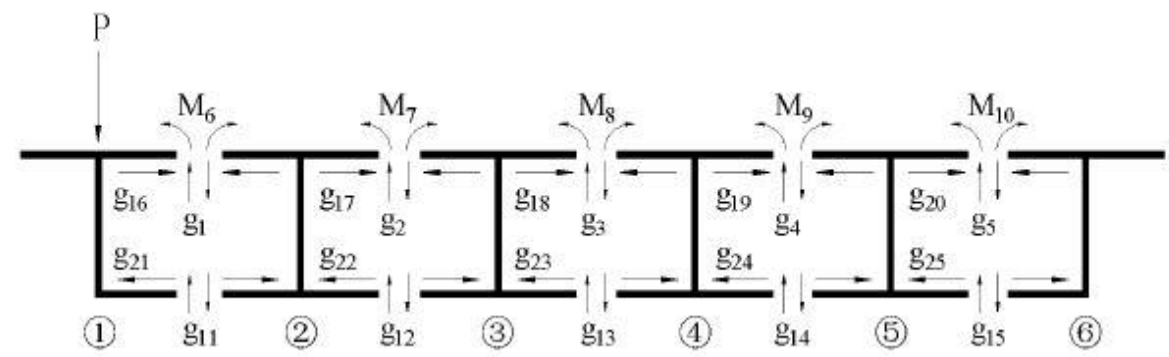

Figure 1. Modified Rigid Beam Method

\section{Half-Wave Sinusoidal Load Equivalent}

When the No.1 beam midspan is subjected to the concentrated force, the slit generates and distributes the vertical shear force in the longitudinal direction and distributes the load on the whole bridge structure. In order to facilitate the analysis of the load distributed on each beam, the concentrated force is equivalent to a continuous distributed load with a sinusoidal distribution ${ }^{[3-6]}$, as shown in Figure 2 and Figure 3.

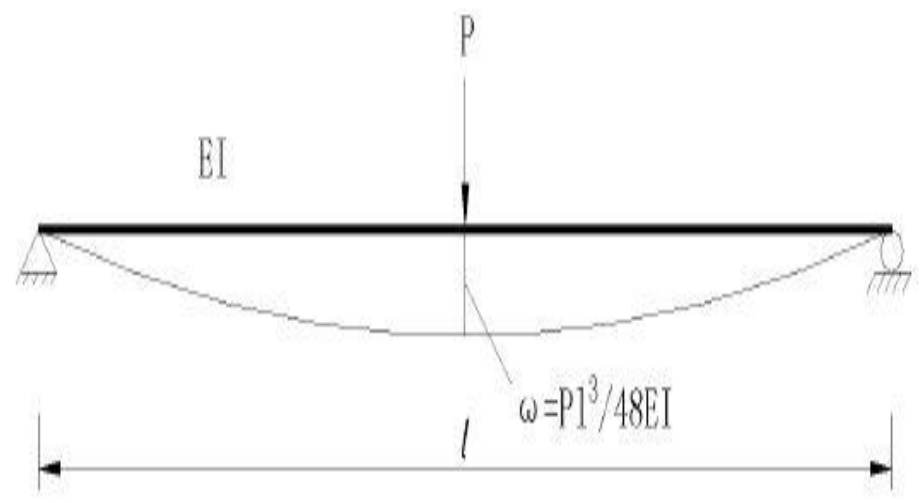

Figure 2. Schematic Diagram of Simply Supported Beam under the Action of $\mathrm{P}=1$ 


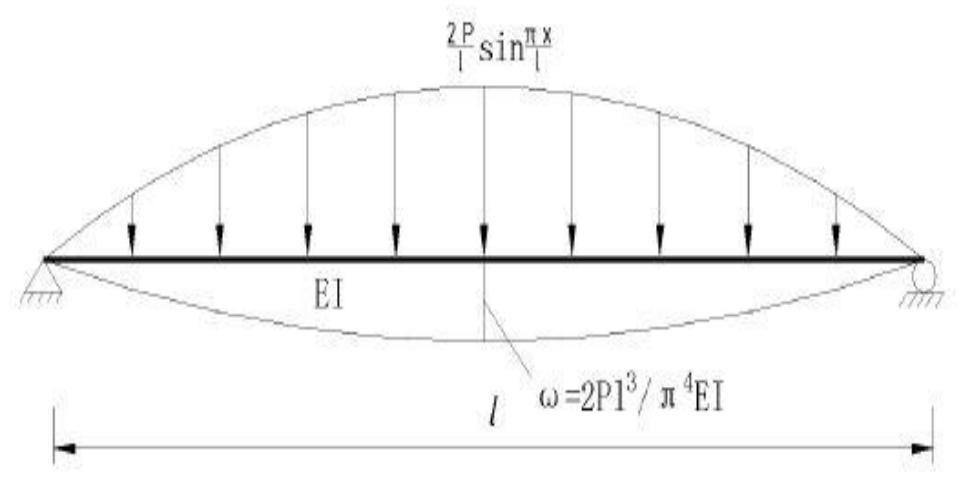

Figure 3. Schematic Diagram of Simply Supported Beam under Sinusoidal Load

Setting the deflection expression as:

$\omega(x)=\sum_{n=1}^{\infty} b_{n} \sin \frac{n \pi x}{l}$

It satisfies the boundary condition of the endpoint

$\mathrm{X}=0.1, \mathrm{w}=0$

$\frac{d^{4} \omega(x)}{d x^{4}}=\sum_{n=1}^{\infty} b_{n}\left(\frac{n \pi}{l}\right)^{4} \sin \frac{n \pi x}{l}$

The equilibrium differential equation is:

$E I \frac{d^{4} \omega(x)}{d x^{4}}=p(x)$

Substituting the formulas (1-8) and $\mathrm{p}(\mathrm{x})=\sin \frac{\pi \mathrm{x}}{\mathrm{l}}$ into (3-9):

EI $\sum_{n=1}^{\infty} b_{n}\left(\frac{n \pi}{l}\right)^{4} \sin \frac{n \pi x}{l}=p(x)=$ $\sin \frac{\pi x}{1}$
The above formula should be treated as bellow, both should be multiplied by $\sin \frac{\mathrm{m} \pi \mathrm{x}}{\mathrm{l}}$, and interval integrals between 0 to 1 are:

$\operatorname{EIb}_{1}\left(\frac{\pi}{1}\right)^{4} \frac{1}{2}=\frac{1}{2}, \quad m=n=1(5)$

As a result:

$b_{1}=\left(\frac{l}{\pi}\right)^{4} \frac{l}{E I}, \quad m=n=1$

$\operatorname{EIb}_{n}\left(\frac{\mathrm{n} \pi}{\mathrm{l}}\right)^{4} \frac{1}{2}=0, \quad \mathrm{~m}=\mathrm{n} \neq 1(7)$

As a result:

$\mathrm{b}_{\mathrm{n}}=0, \quad \mathrm{~m}=\mathrm{n} \neq 1$

$\omega(\mathrm{x})=\frac{2 \mathrm{P}}{\mathrm{EIL}}\left(\frac{\pi}{\mathrm{l}}\right)^{4} \sin \frac{\pi \mathrm{x}}{\mathrm{l}}=\frac{2 \mathrm{Pl}^{3}}{\pi^{4} \mathrm{EI}}$

The rationality of the sinusoidal load equivalent:
1) The midspan deflection is approximately equal:

$\frac{\mathrm{Pl}^{3}}{48 \mathrm{EI}} \approx \frac{2 \mathrm{Pl}^{3}}{\pi^{4} \mathrm{EI}}$

(10)

2) The internal forces $M(x)$ and $\mathrm{Q}(\mathrm{x})$ generated by the sinusoidal load satisfy the simply supported beam boundary condition.

\subsection{Derivation of the Transverse Load Distribution Influence Line}

Since the load is sinusoidal distributed, the shear and bending moments of the beams are sinusoidal distributed. Thus, the transverse distribution of the unit sinusoidal load can be simply expressed by the values of the load and redundants in the center of the bridge span, that is, the peak value of the sinusoidal load:

load horizontal distribution influence line of No. 1 beam, so $\eta_{11}-\eta_{61} \quad$ is the vertical coordinate of the transverse load distribution influence line of No. 1 beam under the 1- 6 beam axis, and $\eta_{i j}$ is the vertical coordinate of the

$$
\begin{gathered}
\eta_{11}=1-g_{1}-g_{11} \\
\eta_{21}=g_{1}+g_{11}-g_{2}-g_{12} \\
\eta_{31}=g_{2}+g_{12}-g_{3}-g_{13} \\
\eta_{41}=g_{3}+g_{13}-g_{4}-g_{14} \\
\eta_{51}=g_{4}+g_{14}-g_{5}-g_{15} \\
\eta_{61}=g_{5}+g_{15}
\end{gathered}
$$


according to the reciprocal theorem of work: $\eta_{\mathrm{ij}}=\eta_{\mathrm{ji}}$.
25 canonical equations can be listed as follows according to the basic structure of Figure 2 above:

$$
\left.\begin{array}{c}
\delta_{1,1} g_{1}+\delta_{1,2} g_{2}+\ldots+\delta_{1,24} g_{24}+\delta_{1,25} g_{25}+\delta_{1, p}=0 \\
\delta_{2,1} g_{1}+\delta_{2,2} g_{2}+\ldots+\delta_{2,24} g_{24}+\delta_{2,25} g_{25}+\delta_{2, p}=0 \\
(12) \\
\delta_{24,1} g_{1}+\delta_{24,2} g_{2}+\ldots+\delta_{24,24} g_{24}+\delta_{24,25} g_{25}+\delta_{24, p}
\end{array}\right\}=0
$$

In the above formula: $\delta_{(\mathrm{i}, \mathrm{k})}$-vertical relative displacement at the cut $i$ caused by the effect unit sinusoidal load at the cut $\mathrm{k}$ $\delta_{(\mathrm{i}, \mathrm{p})}$-vertical displacement at the cut $\mathrm{i}$ caused by the external load $\mathrm{P}$.

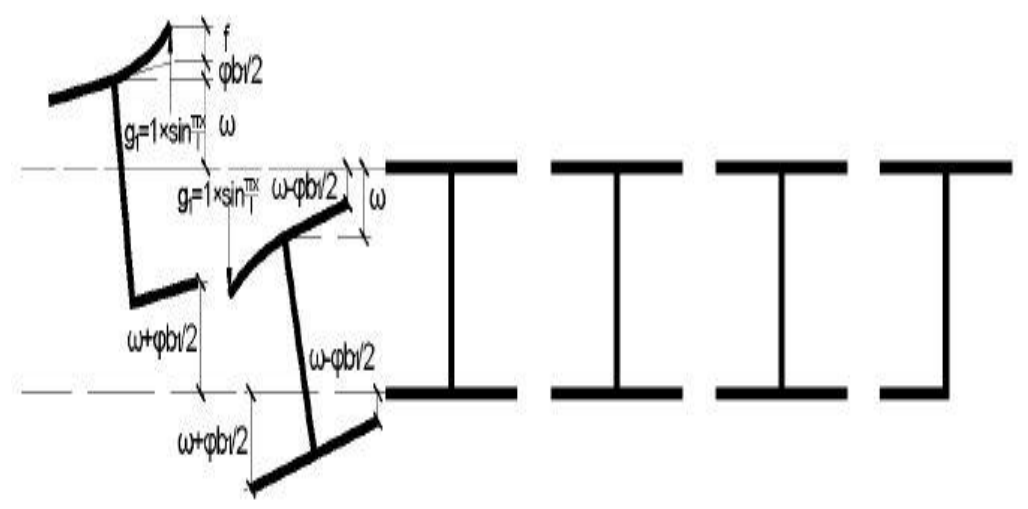

a)

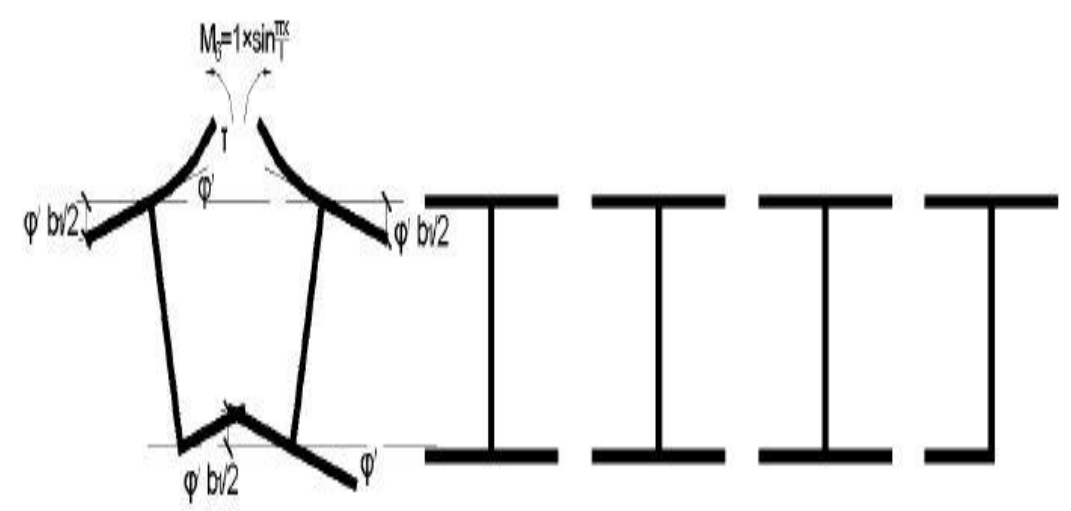

b) 


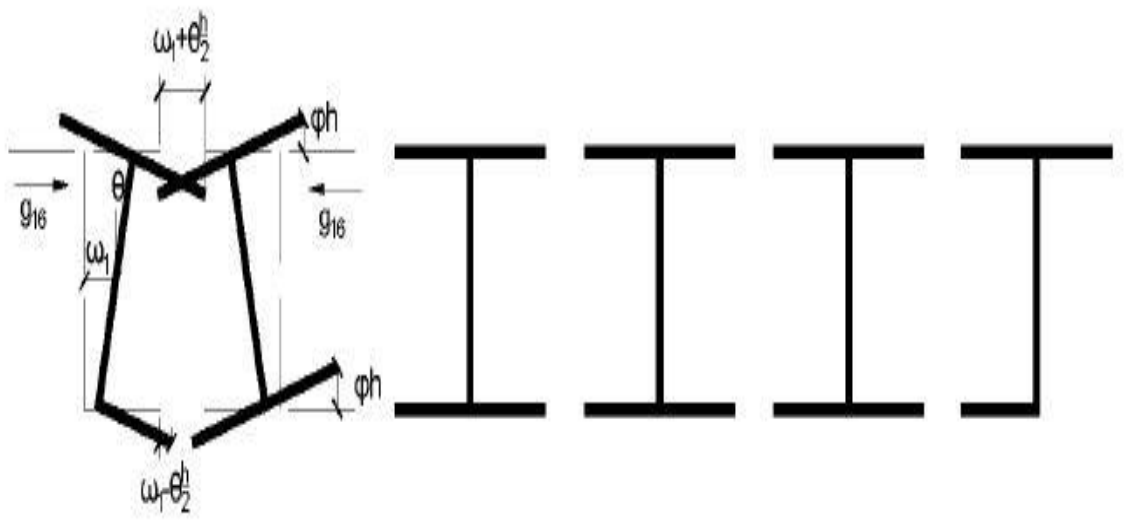

c)

Figure 4. Modified Rigid Jointed Beam Method for the Cut Point Displacement

In Figure 4, a) represents the bridge span central displacement along the direction; Figure b) represents the displacement in the direction of $\mathrm{M}_{6}$; and figure c) shows the displacement along the direction of $\mathrm{g}_{16}$; the displacement along each direction generated by the redundants is similar to that being shown in the figure above, only the subscript changes. Hereby the figure is not necessary; Figure 5, Figure 6 and Figure 7 are the enlarged view of partial displacements generated along $\mathrm{g}_{1}$, $\mathrm{M}_{6}$ and $\mathrm{g}_{16}$ respectively.

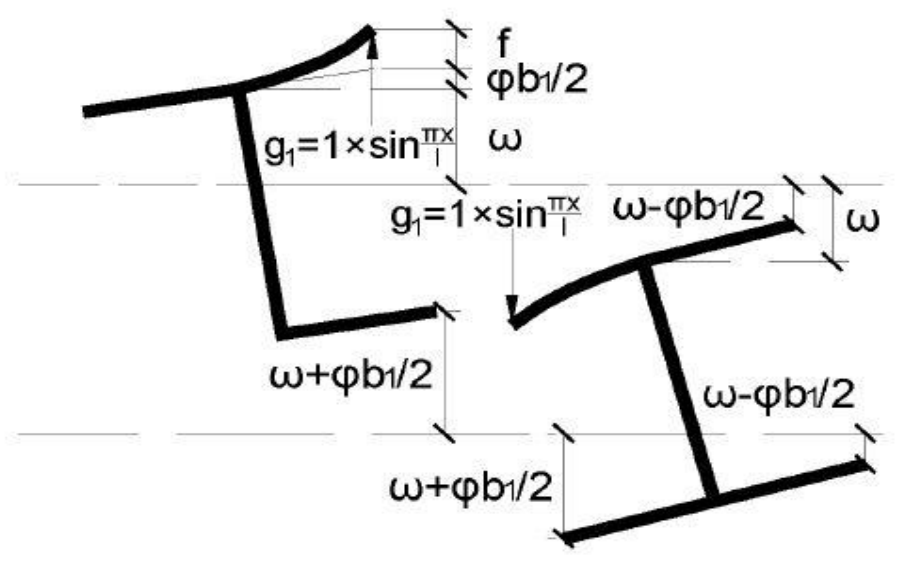

Figure 5. Large Displacement $g_{1}$ Partial Discharge along the Redundants 


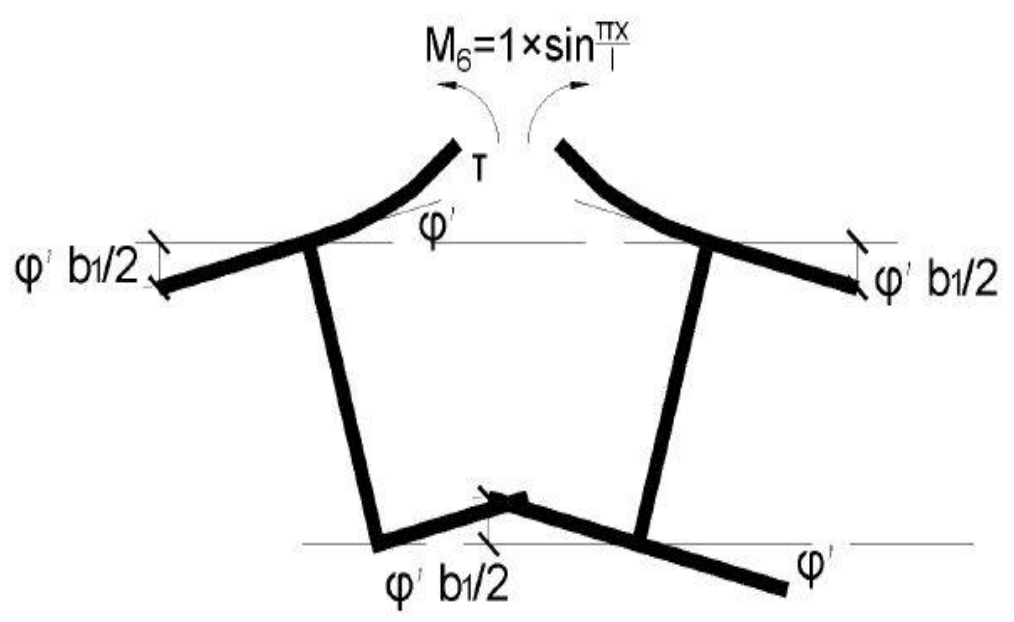

Figure 6. Large Displacement $\mathrm{M}_{6}$ Partial Discharge along the Redundants

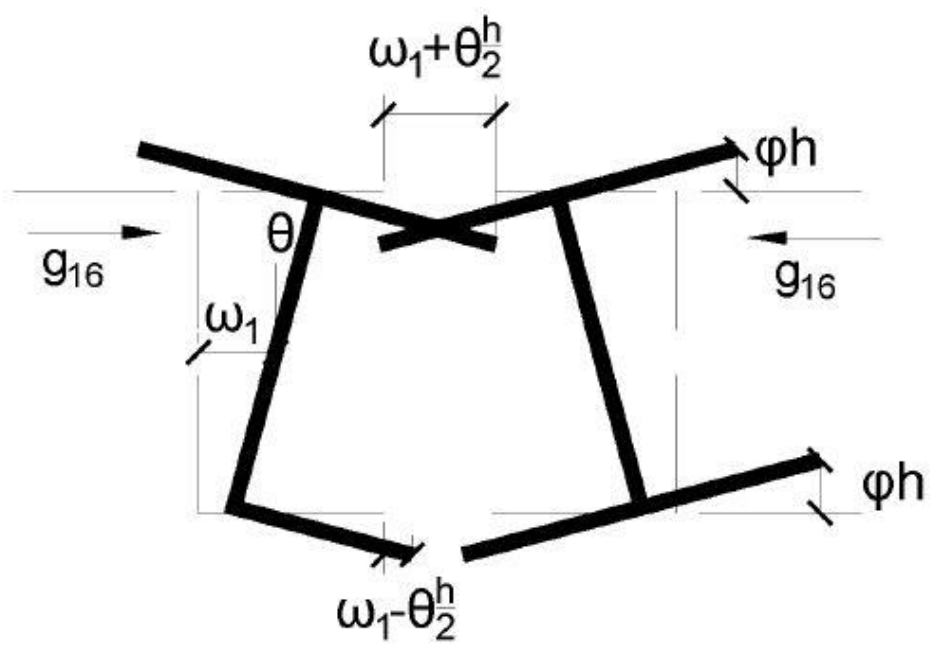

Figure 7. Large Displacement $g_{16}$ Partial Discharge along the Redundants

The coefficient involving only the vertical redundants is subject to the following rules:

$$
\begin{aligned}
& \delta_{1,1}=\delta_{2,2}=\delta_{3,3}=\delta_{4,4}=\delta_{5,5}=\delta_{11,11}=\delta_{12,12} \\
& =\delta_{13,13}=\delta_{14,14}=\delta_{15,15}=2\left(\omega+\varphi \frac{\mathrm{b}}{2}+\mathrm{f}\right) \\
& \delta_{1,2}=\delta_{2,3}=\delta_{3,4}=\delta_{4,5}=\delta_{5,5}=\delta_{11,12}=\delta_{12,13} \\
& =\delta_{13,14}=\delta_{14,15}=\delta_{15,15}=-\left(\omega-\varphi \frac{\mathrm{b}}{2}\right) \\
& \delta_{6,2}=\delta_{7,3}=\delta_{8,4}=\delta_{4,5}=\delta_{9,5}=\delta_{10,4}=\delta_{6,12} \\
& =\delta_{7,13}=\delta_{8,14}=\delta_{9,15}=\delta_{10,14}=-\varphi
\end{aligned}
$$




$$
\begin{aligned}
& \omega=\frac{1^{4}}{\pi^{4} E I} \\
& \varphi=\frac{\mathrm{b}_{1} \mathrm{l}^{2}}{2 \pi^{2} \mathrm{Gl}_{\mathrm{T}}} \\
& f=\frac{d_{1}^{3}}{3 E I_{1}}
\end{aligned}
$$

Where $\mathrm{E}$ and $\mathrm{G}$ are the modulus of elasticity and shear of the material respectively; I-beam cross section vertical bending resistance inertia moment; $\mathrm{I}_{1}$-The transverse bending resistance inertia moment of the unit long flange plate; $\mathrm{I}_{2}$-beam cross section transverse bending resistance inertia moment; $\mathrm{I}, \mathrm{b}_{1}, \mathrm{~d}_{1}$-the torsion inertia moment of the beam; $I_{T}$-are the bridge span length, the widths of the beam cross section and the suspension plate. The deflection at the cantilever end of the main beam flange plate under the sinusoidal load is also the sinusoidal curve $\mathrm{f}(\mathrm{x})=\mathrm{f} * \sin \left(\frac{\pi \mathrm{x}}{\mathrm{l}}\right) \quad$ midspan peak value, which equals to the deflection of the upper flange plate with unit width under the action unit load. The deflection of the upper flange plate is calculated by the bending moment from the plate edge to the flange as shown in Figure 8:

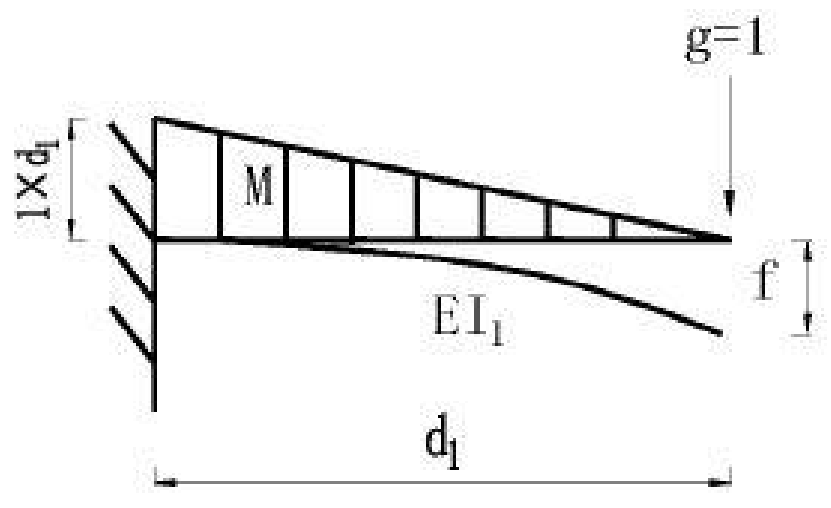

Figure 8. The Deformation of Beams under the Action of Unit Load

The coefficient involving only the excess bending moment is subject to the following rules:

$$
\begin{aligned}
& \delta_{6,6}=\delta_{7,7}=\delta_{8,8}=\delta_{9,9}=\delta_{10,10}=2\left(\varphi^{\prime}+\tau\right) \\
& \delta_{1,7}=\delta_{2,8}=\delta_{3,9}=\delta_{4,10}=\varphi^{\prime} \frac{\mathrm{b}_{1}}{2} \\
& \delta_{6,7}=\delta_{7,8}=\delta_{8,9}=\delta_{9,10}=\varphi^{\prime}
\end{aligned}
$$

The coefficient involving only the transverse redundants is subject to the following rules:

$$
\begin{gathered}
\delta_{16,16}=\delta_{17,17}=\delta_{18,18}=\delta_{19,19}=\delta_{20,20}=\delta_{21,21} \\
=\delta_{22,22}=\delta_{23,23}=\delta_{24,24}=\delta_{25,25}=2\left(\omega_{1}+\theta \frac{\mathrm{h}}{2}\right) \\
\delta_{1,17}=\delta_{2,18}=\delta_{3,19}=\delta_{4,20}=\delta_{1,22}=\delta_{2,23}=\delta_{3,24} \\
=\delta_{11,17}=\delta_{12,18}=\delta_{13,19}+\delta_{14,20}+=-\theta \frac{\mathrm{b}_{1}}{2}
\end{gathered}
$$




$$
\begin{gathered}
\delta_{16,17}=\delta_{17,18}=\delta_{18,19}=\delta_{19,20}=\delta_{16,22}=\delta_{17,23} \\
=\delta_{18,24}=\delta_{19,25}=\delta_{25,19}=\delta_{21,17}=\delta_{22,18}=\delta_{23,19} \\
=\delta_{24,20}=\delta_{21,22}=\delta_{22,23}=\delta_{23,24}=\delta_{24,25} \\
=\delta_{25,24}=-\left(\omega_{1}+\theta \frac{\mathrm{h}}{2}\right)
\end{gathered}
$$

Being caused by the unit transverse sine bending moment, the midspan twist angle of the beam is $\varphi^{\prime}$, and the deflection of the suspension plate is $\tau$. Under the action of the transverse unit sinusoidal load, the midspan transverse deflection is $\omega_{1}$ and the twist angle is $\theta$. Wherein $\tau$ of the I-beam with the flange cantilever $d_{1}$ is calculated as shown in Figure 9.
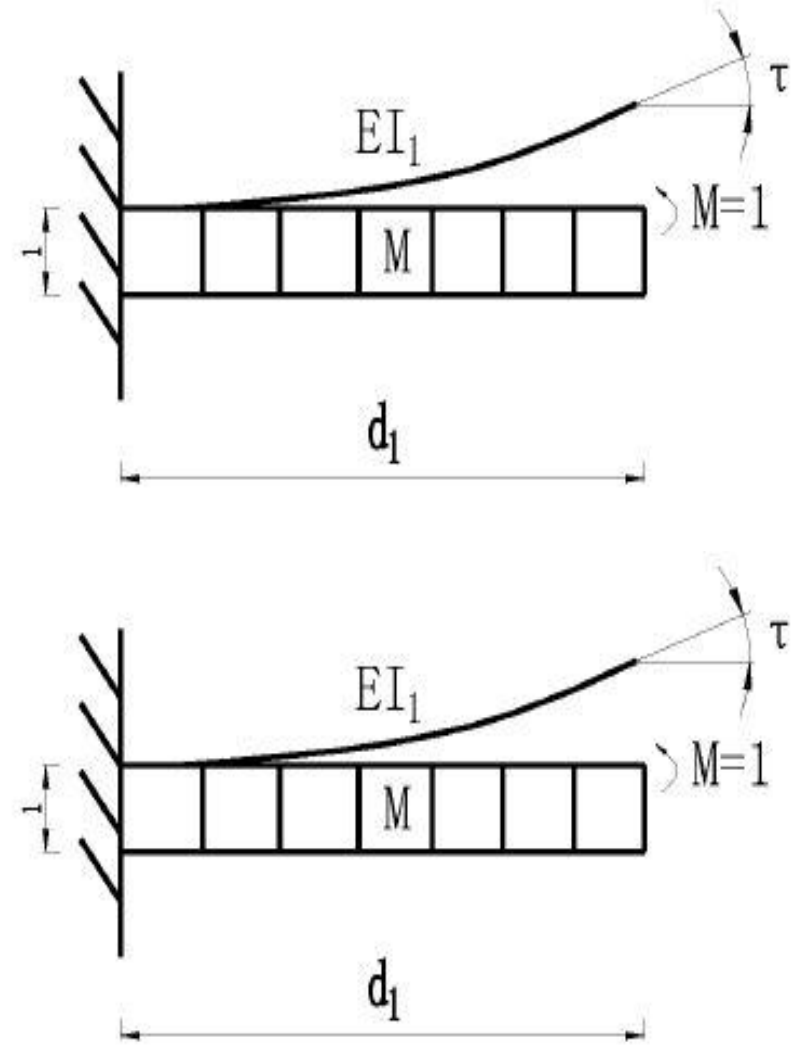

Figure 9. Deflection of the Beam under the Bending Moment of 1 Units

It can be obtained according to the material and the structural mechanic formulas:

$$
\begin{aligned}
& \tau=\frac{1 \cdot \mathrm{d}_{1}}{\mathrm{EI}_{1}} \\
& \varphi^{\prime}=\varphi \frac{1}{\mathrm{~b}_{1} / 2}=\frac{2 \varphi}{\mathrm{b}_{1}} \\
& \theta=\frac{\mathrm{hl}^{2}}{2 \pi^{2} \mathrm{GI}_{\mathrm{T}}} \\
& \omega_{1}=\frac{\mathrm{l}^{4}}{\pi^{4} \mathrm{EI}_{2}}
\end{aligned}
$$


When the unit sinusoidal load acts on the No. 1 beam, the load factor can be obtained (when acting on other beams, it can be treated similarly):

In addition, it can write:

$$
\left.\begin{array}{c}
\delta_{1, \mathrm{p}}=\delta_{11, \mathrm{p}}-\omega \\
\delta_{2, \mathrm{p}}=\delta_{3, \mathrm{p}}=\ldots=\delta_{10, \mathrm{p}}=0 \\
\delta_{12, \mathrm{p}}=\delta_{13, \mathrm{p}}=\ldots=\delta_{25, \mathrm{p}}=0
\end{array}\right\}
$$

\section{$\delta_{5,20}$}

$$
\Delta_{1,6}=\delta_{2,7}=\delta_{3,8}=\delta_{4,9}=\delta_{5,10}=\delta_{1,16}=\delta_{2,17}=\delta_{3,18}=\delta_{4,19}=
$$

$\delta_{1,9}$

$$
=\delta_{1,21}=\delta_{2,22}=\delta_{3,23}=\delta_{4,24}=\delta_{5,25}=\delta_{1,3}=\delta_{1,4}=\delta_{1,5}=\delta_{1,8}=
$$

$\delta_{1,24}$

$$
=\delta_{1,10}=\delta_{1,13}=\delta_{1,14}=\delta_{1,15}=\delta_{1,18}=\delta_{1,19}=\delta_{1,20}=\delta_{1,23}=
$$

$$
=\delta_{1,25}=\delta_{2,4}=\delta_{2,5}=\delta_{2,7}=\delta_{2,9}=\delta_{2,10}=\delta_{2,14}=\delta_{2,15}=\delta_{2,17}=
$$

$\delta_{2,19}$

$$
=\delta_{2,20}=\delta_{2,22}=\delta_{2,24}=\delta_{2,25}=\delta_{3,8}=\delta_{3,10}=\delta_{3,11}=\delta_{3,13}=\delta_{3,15}=
$$

$\delta_{3,16}$

$\delta_{4,12}$

$$
=\delta_{3,18}=\delta_{3,20}=\delta_{3,21}=\delta_{3,23}=\delta_{3,25}=\delta_{4,6}=\delta_{4,7}=\delta_{4,9}=\delta_{4,11}=
$$

$$
\begin{aligned}
& =\delta_{4,14}=\delta_{4,16}=\delta_{4,17}=\delta_{4,19}=\delta_{4,21}=\delta_{4,22}=\delta_{4,24}=\delta_{5,6}=\delta_{5,7}= \\
\delta_{5,8} & =\delta_{5,10} \\
& =\delta_{5,11}=\delta_{5,12}=\delta_{5,13}=\delta_{5,15}=\delta_{5,17}=\delta_{5,18}=\delta_{5,20}=\delta_{5,21}=\delta_{5,22}=
\end{aligned}
$$

$\delta_{5,25}$

$$
=\delta_{6,8}=\delta_{6,9}=\delta_{6,10}=\delta_{6,13}=\delta_{6,15}=\delta_{6,18}=\delta_{6,19}=\delta_{6,20}=\delta_{6,23}=
$$

$\delta_{6,24}$

$$
\begin{aligned}
=\delta_{6,25}=\delta_{7,9}= & \delta_{7,10}=\delta_{7,14}=\delta_{7,15}=\delta_{7,19}=\delta_{7,20}=\delta_{7,24}=\delta_{7,25}=\Delta_{8,10}=\delta_{8,11} \\
= & \delta_{8,15}=\delta_{8,16}=\delta_{8,20}=\delta_{8,21}=\delta_{8,25}=\delta_{9,11}=\delta_{9,12}=\delta_{9,16}=\delta_{9,17}=
\end{aligned}
$$

$\delta_{9,21}$

$$
=\delta_{9,22}=\delta_{10,11}=\delta_{10,12}=\delta_{10,13}=\delta_{10,16}=\delta_{10,17}=\delta_{10,18}=\delta_{10,21}=
$$

$\delta_{10,22}$

$$
=\delta_{10,23}=\delta_{11,13}=\delta_{11,14}=\delta_{11,15}=\delta_{11,18}=\delta_{11,19}=\delta_{11,20}=\delta_{11,21}=
$$

$\delta_{11,23}$

$$
\begin{aligned}
& =\delta_{11,24}=\delta_{11,25}=\delta_{12,14}=\delta_{12,25}=\delta_{13,15}=\delta_{13,16}=\delta_{13,20} \\
& =\delta_{13,21}=\delta_{13,23}=\delta_{13,25}=\delta_{14,16}=\delta_{14,17}=\delta_{14,21}=\delta_{14,22}=\delta_{14,24}=\delta_{15,16}
\end{aligned}
$$




$$
\begin{aligned}
& =\delta_{15,18}=\delta_{15,21}=\delta_{15,22}=\delta_{15,23}=\delta_{15,25}=\delta_{16,18}=\delta_{16,19}=\delta_{16,20}=\delta_{16,23} \\
& =\delta_{16,24}=\delta_{16,25}=\delta_{17,19}=\delta_{17,20}=\delta_{17,24}=\delta_{17,25}=\delta_{18,20}=\delta_{18,21}=\delta_{18,25} \\
& =\delta_{19,21}=\delta_{19,22}=\delta_{20,21}=\delta_{20,22}=\delta_{20,23}=\delta_{21,23}=\delta_{21,24}=\delta_{21,25}=\delta_{22,24}=\delta_{22,25}=\delta_{23,25}=0
\end{aligned}
$$

The remaining coefficients can be obtained according to the reciprocity theorem of the work. There is no more detailed description.

Hereby, the coefficient $\delta_{i, j}$ has been fully calculated. All the redundants are solved after substituting the coefficient into the canonical equation and the solving polynomial matrix equation. The transverse load distribution influence line is calculated through the formula. To solve the rigid jointed beam method canonical equation, $\delta_{i, p}$ can be moved to the right of the equation, and both sides of the equation are divided by the displacement $\omega$.

\section{Modified Rigid Jointed Beam Method Calculation Procedures and Essentials}

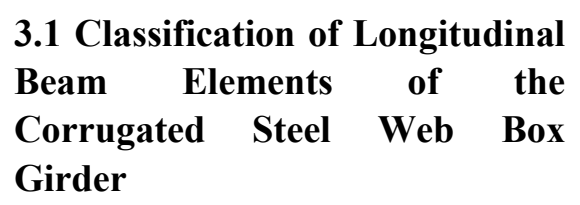

The treatment of corrugated steel webs applied by the "modified rigid jointed beam method" is the same with that of the traditional "rigid jointed beam method". That is, with the conversion conditions that the total shear force and the shear strain are the same, the cross section of the corrugated steel web is converted to that of the equivalent concrete with corresponding thickness as shown in Figure 10.

$$
\mathrm{t}_{\mathrm{e}}=\frac{\mathrm{G}_{\mathrm{e}} \mathrm{t}}{\mathrm{G}_{\mathrm{c}}}=\mathrm{n}_{0} \mathrm{t}
$$

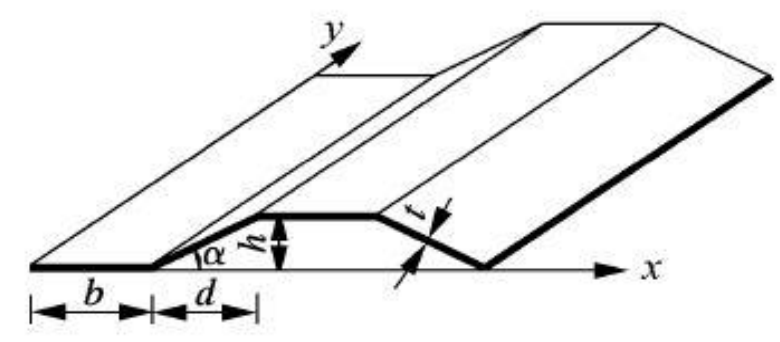

Figure 10. Structural Shape of Corrugated Steel Webs

Among them:

$\mathrm{n}_{0}=\frac{\mathrm{G}_{\mathrm{e}}}{\mathrm{G}_{\mathrm{c}}}$ is the ratio between the corrugated steel web equivalent shear modulus and the concrete shear modulus;

$\mathrm{G}_{\mathrm{e}}=\frac{\mathrm{b}+\mathrm{d}}{\mathrm{b}+\mathrm{dsec} \alpha} \mathrm{G}_{0}, \mathrm{G}_{0}$ is the steel shear modulus, and the meanings of $b, d, \alpha$ are shown in Figure 10.
After the equivalent treatment of the corrugated steel web box girder bridge as described above, the original corrugated steel box girder bridge is equivalent to the corresponding concrete web box girder bridge. The single box double chamber corrugated steel box girder is taken as an example to illustrate. As shown in Figure 11 (equivalent conversion of the box girder), the equivalently conversed box girder of the single-box double-chamber cross section is cut into the structure composed by the I-beam. The centroids of each I-beam are on the main axis of the superstructure. In this case, one-third of the top board and one-third of the bottom board are reckoned in for each beam. The inertia moment of each beam is one-third of the total inertia moment of the upper structure ${ }^{[7]}$. 


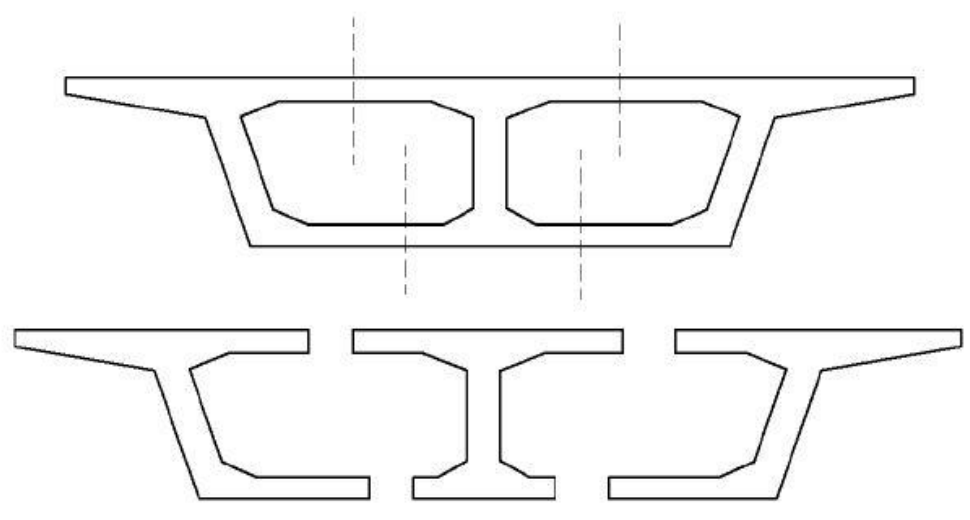

Figure 11. Single box and double chamber section

For the superstructure of the single-box multi-chamber cross section, it is impossible to section in accordance with Figure 10 generally. Thus, the box girder can only be cut along the top and bottom boards in the middle of the two webs as shown in Figure 12. Thus, the centroids of the center beam coincide with the main axis of the upper structure, and the centroids of both sides of the I-beam are on the horizontal line near the top board, but their inertia moments are calculated according to the overall structure of the spindle. Thus, the vertical I-beam of the "modified rigid jointed beam method" proposed by the paper is classified according to the method indicated by Figure 11.

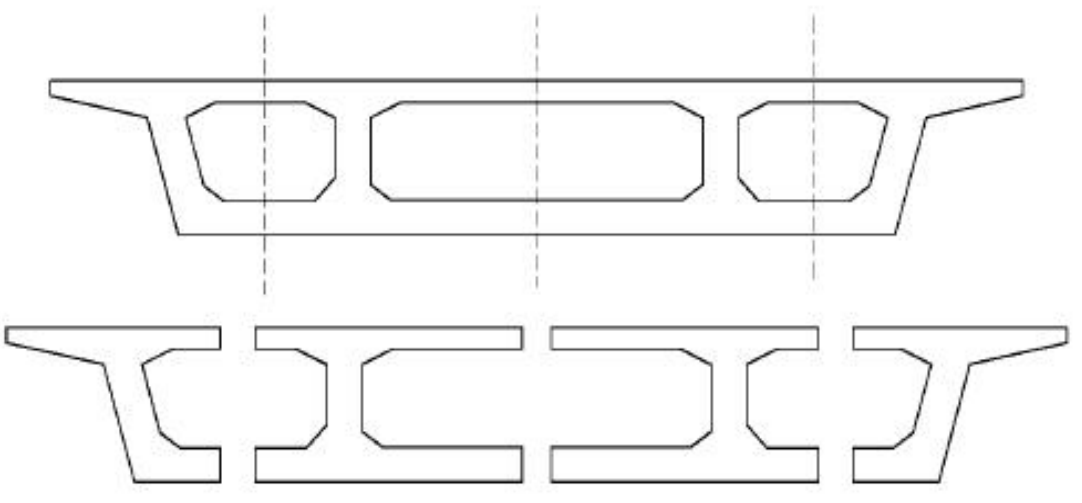

Figure 12. Multi-box Section

\subsection{Determination of Cross Section Characteristics}

\subsubsection{Bending rigidity}

As shown in Figure 12, the equivalent box girder structure along the top and bottom boards are cut into the structure composed by the I-beam. The bending stress distribution is shown in Figure 13, which is similar to the result of the simply supported beam theory. 


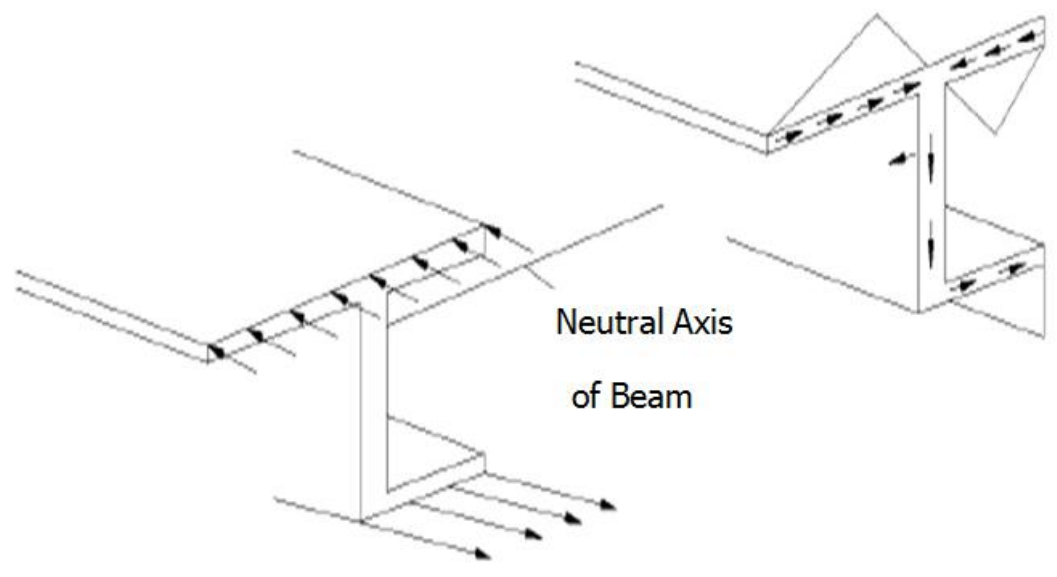

Figure 13. Normal Stress and Shear Stress Generated by the Bending of the Side Beam Around the Self-neutral Axis

$\frac{\delta}{\mathrm{z}}=\frac{\mathrm{M}}{\mathrm{I}}=\frac{\mathrm{E}}{\mathrm{R}}$

$$
\tau=\frac{\mathrm{Q}_{\mathrm{M}} \mathrm{A} \overline{\mathrm{z}}}{\mathrm{I}}
$$

Vertical Shear Stress Produced by Bending of I - beam:

$$
\mathrm{Q}_{\mathrm{M}}=\frac{\mathrm{dM}}{\mathrm{dx}}
$$

$\mathrm{Q}_{\mathrm{M}}$ is part of the web shearing force, and the web has the shear component due to the torsion $\mathrm{Q}_{\mathrm{T}}$.

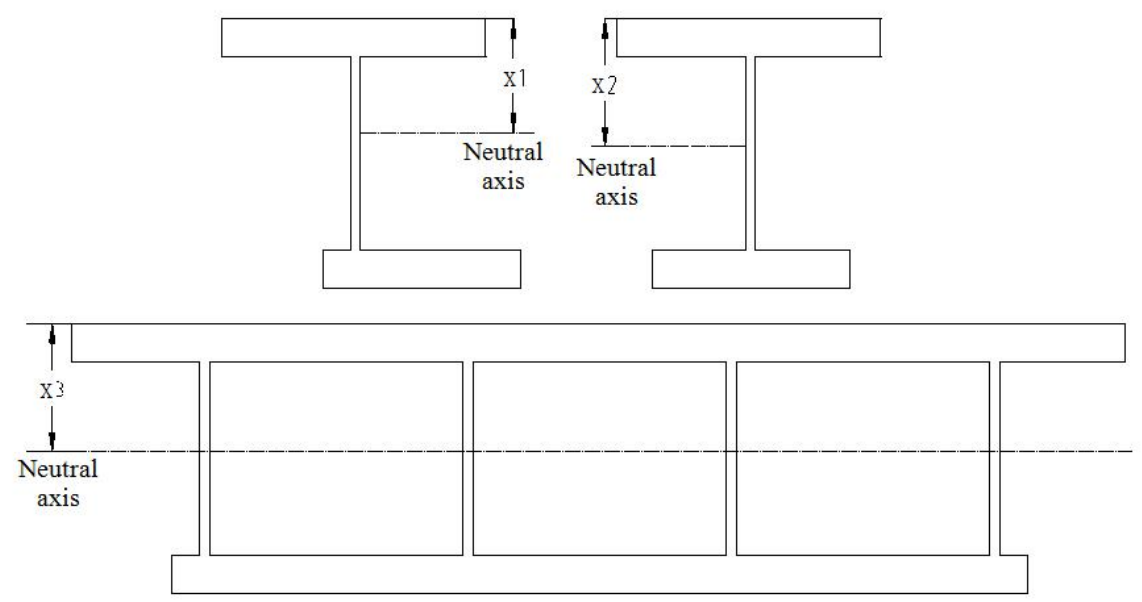

Figure 14. Schematic Diagram of the Position of the Neutral Axis of the Beam

In Figure 14, the neutral axis of the I-beam will not be on the same horizontal line, and $\mathrm{x}_{1}, \mathrm{x}_{2}$ and $\mathrm{x}_{3}$ are not equal, which is inconsistent with the situation of the actual structure. The actual engineering structure, the corrugated steel web box girder is bent under the action of the load and should be bent around the same neutral axis. Thus, the cross section characteristic of each I-beam represented by the stringer element should be calculated according to the overall superstructure. Though the suspension plate may be larger, and the thickness of the edge and the middle webs is different, it is proper to cut the superstructure along the longitudinal direction. 
When the suspension plate is large or the flange is wide, consider the effective width of the cross section.

In summary, the bending stiffness of each beam cross section is: EI

E-the elastic modulus.

I-the inertia moment applied by the cross section of each beam on the neutral axis of the box girder.

\subsubsection{Torsional rigidity}

In this chapter, the effect of the cross section distortion is not taken into account for the value choosing for the box girder torsional rigidity. When the box girder is twisted as a whole, the shear stress flows in the cross section of the structure as being concluded based on the previous analysis result. As shown in Figure 15 and 16, most of the shear stress flows around the top and bottom boards and webs on both sides, and a small amount flows through the middle web. The shear stress flow of the inner web of the multi-chamber is relatively small and can be ignored as being compared with that of webs on both sides. The inner web stress flow from both sides to the middle of the web is gradually reduced. The middle inner web stress flow can be regarded as zero ${ }^{[8]}$. It can be concluded that it is not necessary to consider the inner web for the torsional stiffness of the corrugated steel web box girder under the action of the torsional load. After cutting the box girder between the webs, the total torque in the box girder is composed of the longitudinal beam element torque and its shear force $Q_{r}$, where the longitudinal beam element torque represents the torque formed in the upper structure due to the opposite shear stress in the top and bottom boards, while the sheer force $Q_{T}$ represents the stress flow in the web; ${ }^{[9-12]}$ thus, the torsional rigidity of the longitudinal beam element is:

$$
\mathrm{GJ}_{\mathrm{X}}
$$

G-the shear modulus

$\mathrm{J}_{\mathrm{X}}$-(the inertia moment of the top and bottom boards flanges represented by the longitudinal beam element on the central axis)

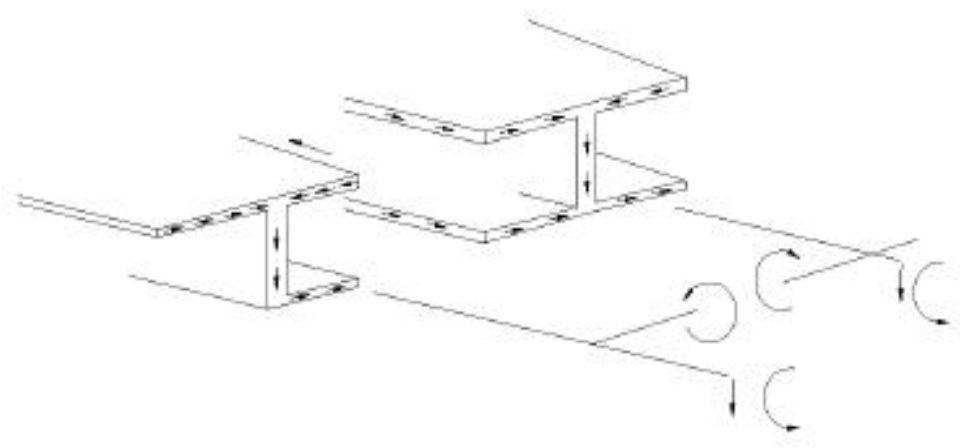

Figure 15. Shear Distribution of Cross Section under Torsion
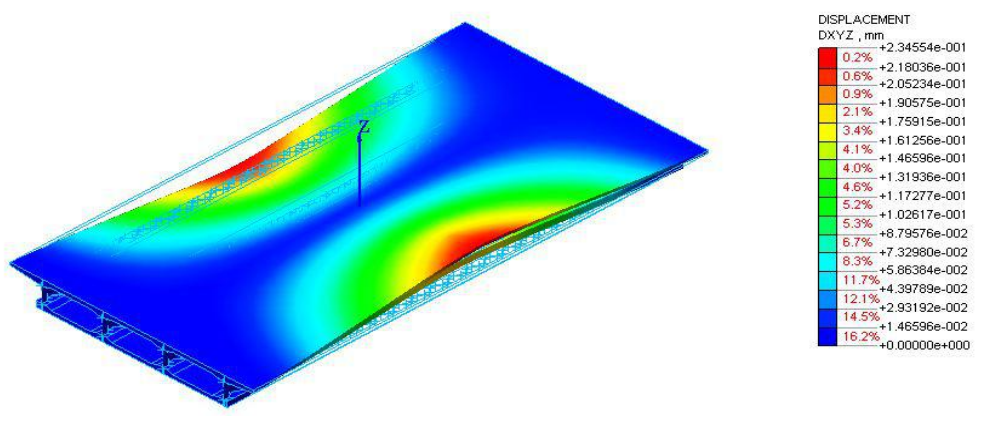

(a) axis mapping 


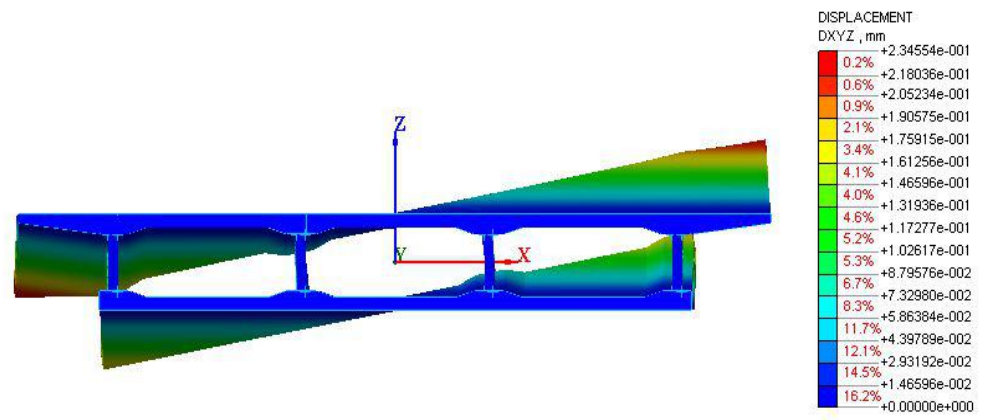

(b) positive view

Figure 16. Vertical displacement cloud after torsional loading

\subsection{Calculation Procedures of the "Modified Rigid Jointed Beam Method" Transverse Distribution Influence Lines}

The treatment of corrugated steel webs applied by the "modified rigid jointed beam method" is the same with that being indicated above. That is, the corrugated steel web is equivalent to the concrete slab with corresponding thickness. Then it is calculated according to the method described in the paper. ${ }^{[13-15]}$

$$
\mathrm{t}_{\mathrm{e}}=\frac{\mathrm{G}_{\mathrm{e}} \mathrm{t}}{\mathrm{G}_{\mathrm{c}}}=\mathrm{n}_{0} \mathrm{t}=15(\mathrm{~mm})
$$

After equivalent conversion, the concrete web box girder with the corresponding thickness is obtained
In order to reflect calculation procedures and rules of the "modified rigid jointed beam method" visually, this section takes the single-box three-chamber box girder for example to specifically describe the transverse distribution coefficient calculation method of the single-box multi-chamber corrugated steel web box girder of the "modified rigid jointed beam method".
For the transverse load distribution of the box girder calculated by the "modified rigid jointed beam method", the calculated span is $20 \mathrm{~m}$ and the bridge width is $16 \mathrm{~m}$.

The calculation of the transverse distribution influence line of the "modified rigid jointed beam method":

(1) The thickness of the equivalent concrete web:

classification, the single-box three-chamber cross section box girder is cut along the web into the structure composed by the I-beam, as shown in Figure 18.

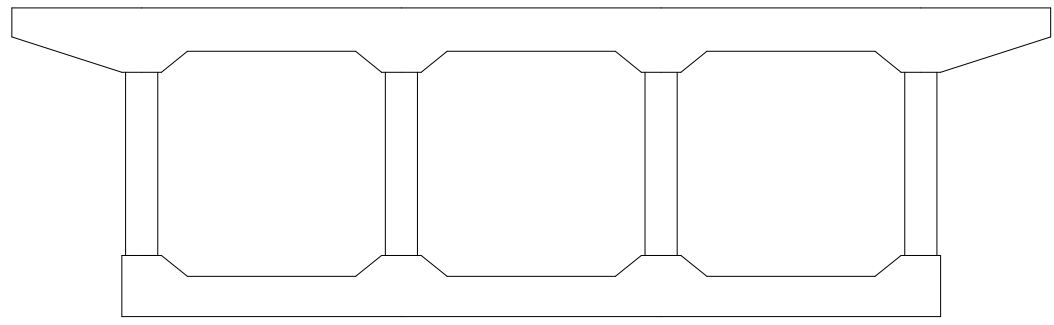

Figure 17. Transverse Section of Box Girder 

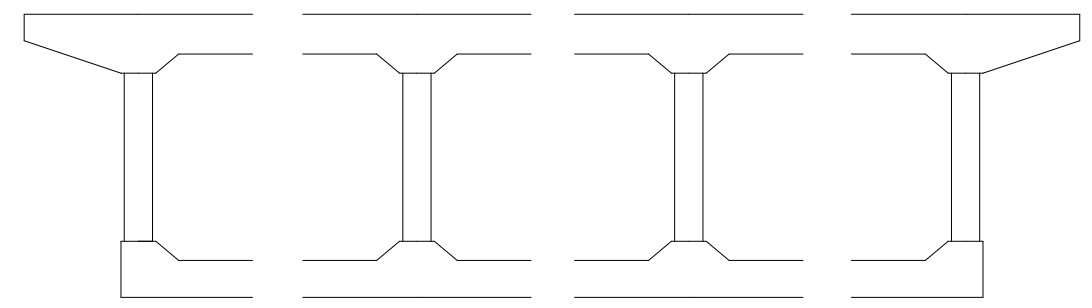

(1) (2) (3) (4)

Figure 18. Single Box and Three Section Box Girder Section Cut

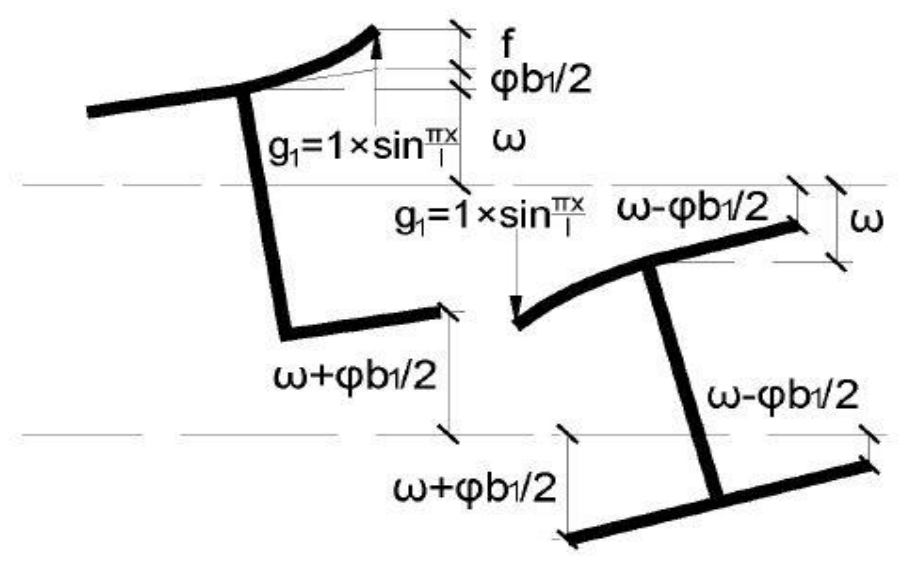

Figure 19. Large displacement g1 partial discharge along the redundants

When $\mathrm{q}(\mathrm{x})=\frac{2 \mathrm{P}}{\mathrm{l}} \sin \frac{\pi \mathrm{x}}{\mathrm{l}}$ is on top of the No. (1) beam shown in Figure
19, the transverse distribution coefficient is calculated according to the formula (11):

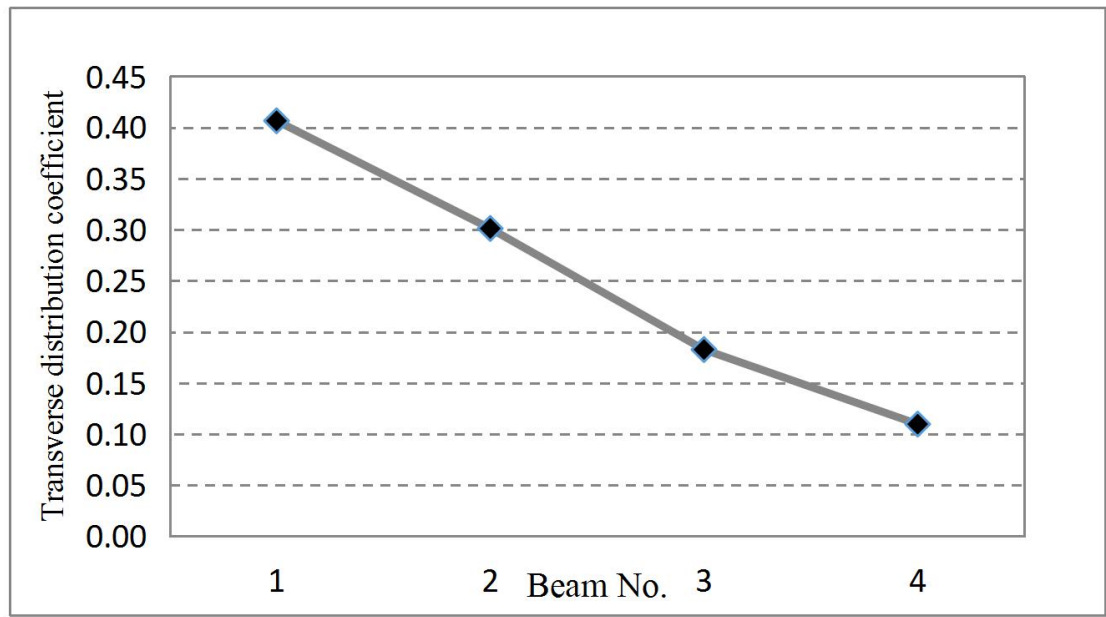

Figure 20. Influence Line of Transverse Distribution of No. (1) Beam Load

No. (1) beam: 


$$
\begin{gathered}
\eta_{11}=1-g_{1}-g_{11}=0.41 \\
\eta_{21}=g_{1}+g_{11}-g_{2}-g_{12}=0.30 \\
\eta_{31}=g_{2}+g_{12}-g_{3}-g_{13}=0.18 \\
\eta_{41}=g_{3}+g_{13}=0.11
\end{gathered}
$$

Similarly, transverse distribution coefficient of the load acted on tops on beams (2), (3) and (4) can be calculated and there is no need to be repeated hereby. The above are the calculation procedures using the "modified rigid jointed beam method" to obtain the transverse distribution coefficient of the corrugated steel web box girder.

\section{The "Modified Rigid Jointed Beam Method" Calculation Programming}

After the chambers of the multi-chamber corrugated steel web box girder are added, the number of $\delta_{i, j}$ coefficients in the canonical equation increases orderly. If it is still calculated manually, the cumbersome calculation process will greatly increase the probability of workload and error. In order to improve the situation, the paper compiles the solver of the redundants of the "modified rigid jointed beam method" through the simulation software Matlab. ${ }^{[16-19]}$

Matlab is a powerful and computationally efficient mathematical tool developed by the American company MathWorks in C language, which is called Matrix Laboratory. At the beginning, Matlab can only carry on the matrix computation. Due to the enhancement of computer and programming technologies, Matlab's function has also been perfected constantly, with the addition of functions including the numerical computation, the symbol operation as well as the graphic processing, etc. Matlab is widely used, covering almost all areas of scientific and engineering computing, such as automatic control, vibration theory, optimization design, timing analysis and modeling, neural network control, digital signal processing, chemical statistics, dynamic simulation system, special functions, etc. Matlab, in addition to its powerful computing functions, is an advanced computer language, which can be used to do programming. Matlab computer language is called "The Language of the Mathematic Version". Compared with advanced computer languages, including Fortran and $\mathrm{C}$ language, etc., Matlab, with simpler grammar rules and being closer to the general way of thinking, liberates programmers, especially non-professional origin programmers from writing cumbersome codes. Using Matlab to write programs is as intuitional as deriving a formula on the paper. Thus, it is also known as "Draft Paper" scientific engineering algorithm language. It follows that Matlab language is simple, natural and easy to learn and use.

Being a plain text file and called as $M$ file with the expanded name .m, Matlab program file can be divided into scripting and functional types, which can be used to edit with any word processing software. Matlab itself is an interpretation system. The implementation of the function program is in a way explanation. The program can run directly without being compiled, and report and analyze the cause of the error occurred in time. Thus, the program debugging is easy with high programming efficiency.

In addition, Matlab has developed a powerful set of modules or toolboxes for many specialized fields and users can use these toolboxes directly without having to write their own code. At present, Matlab has expanded the scope of the toolboxes to many fields of the scientific research and engineering applications. In order to make full use of various resources, Matlab has developed interfaces with other practical programs, which makes it easy to dock with Fortran, $\mathrm{C}$ and other languages to achieve mixed programming. ${ }^{\text {[20-22] }}$

The solver of the "rigid jointed beam method".

The basic solution unit of Matlab is a matrix whose instruction expressions are very close to that of mathematics and engineering. For example, the matrix $\mathrm{BX}=\mathrm{A}$, expressed as $\mathrm{B}^{*} \mathrm{X}=\mathrm{A}$ in the Matlab software. $\mathrm{X}$ is solved by the expression $\mathrm{X}=\mathrm{B} / \mathrm{A}$. There is no need to program the matrix multiplication and the inversion. Thus, it is simpler to use Matlab to solve the matrix than using languages including $\mathrm{C}$ and Fortran, etc. In the process of solving the redundants, moving to the right side of the equation to solve the following matrix $\delta_{\mathrm{i}, \mathrm{p}}\left[\delta_{\mathrm{i}, \mathrm{p}}\right]\left[\mathrm{X}_{\mathrm{i}}\right]=$ $\left[\delta_{\mathrm{i}, \mathrm{p}}\right] .{ }^{[23]}$

For the solution of the matrix, $\delta_{\mathrm{i}, \mathrm{p}}$ will be moved to the right of the equation and then the equation is divided by the displacement $\omega$ of both sides. In this way, all the coefficients are only related to the 
cross section parameters and the calculation span of the box girder during the solving process, with no relations to elastic model $\mathrm{E}$. The following figure is a flow chart that uses the solver to solve the matrix.

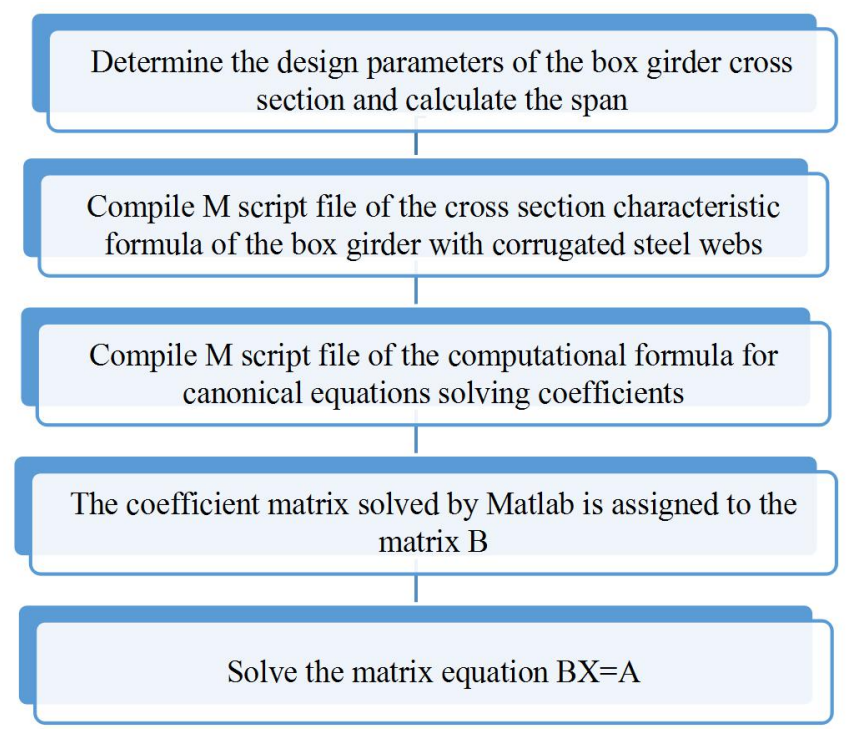

Figure 21. "The Modified Rigid Beam Method" for Solving the Redundants Program Flow Chart

For the Figure 21 of solving the redundants program flow chart, Matlab will automatically calculate by $M$ script file as long as the corrugated steel web box girder cross section parameters are input during the second and the third steps; according to the "modified rigid jointed beam method" derivation process, it can be concluded that: In the case of each additional chamber of multi-chamber, the number of redundants is increased, and the coefficients $\delta_{i, p}$ in the canonical equations are increased by the square of the number of redundants. The change rule is obtained. The coefficients solved by the third step are given the matrix $\left[\delta_{i, p}\right]$. Then all the redundants at the cut of the corrugated steel web box girder are solved by the solver.

\section{Conclusions}

In this paper, the "modified rigid jointed beam method" is introduced in detail and the formula is given based on the calculation principle of the "traditional rigid jointed beam" of the corrugated steel web composite box girder. The conclusions are as follows:

1) Based on the "traditional rigid jointed beam method" algorithm of the corrugated steel web composite box girder transverse distribution coefficient and combining with the existing research results of the stress distribution of the roof plate and the web of the corrugated steel web composite box girder, the conclusion is that the key to the modification of the "rigid jointed beam method" is to supplement the redundants at the cut of the top and bottom boards, that is, the redundants at the incision of the top board is the transverse bending moment, and of the bottom board is the lateral shear force and the transverse force. ${ }^{[24]}$

2) Through the mechanical analysis, this paper abstracts the basic mechanics calculation model of the "modified rigid jointed beam method" and obtains the formula of "modified rigid jointed beam method" of corrugated steel web composite box girder by solving the corresponding force equation.

3) The process of "modified rigid jointed beam method" to calculate the transverse distribution coefficient of corrugated steel web composite box girder is: The steel web of the corrugated steel web composite box girder is equivalent to the corresponding concrete web through the equivalent stiffness principle. ${ }^{[25]}$ Then, the transverse distribution coefficient of a cross section is solved by the force method equation established according to the computational scheme of the corresponding box chamber.

4) After the corrugated steel web composite box girder is equivalent to the concrete web box girder, the top and bottom boards along the web are cut into I-beams, the stress of which should be the same with that of the original box girder. Thus, the neutral beam of the original box 
girder is used as the neutral axis of each I-beam to do relevant calculations of the corrugated steel web composite box girder.

5) The number of parameters of the basic force method equation of the "modified rigid jointed beam method" of the corrugated steel web composite box girder increases with that of the box chamber of the corrugated steel web composite box girder. That is, the number of parameters will increase by 5 when 1 chamber is added. ${ }^{[26]}$ In order to simplify the calculation, this paper gives the programming ideas of "modified rigid jointed beam method", which can be used as a reference for relative scientific and research personnel to solve the transverse distribution coefficient of corrugated steel web composite box girder.

\section{References}

[1] Fang Wang. Experimental Study on Mechanical Behavior of Composite Box-Girder with Corrugated Steel Webs[D]. Changsha:Hunan University, 2007. (in Chinese)

[2] Yu Liao. Study on Several Special Mechanical Behavior of Composite Box-Girder with Corrugated Steel Webs[D]. Beijing: North Jiaotong University, 2011. (in Chinese)

[3] Jihong Yuan. Study on the Load Transverse Distribution of Simply Supported Beam Bridge Using Half-Wave Sinusoidal Load Instead of Concentrated Force [C].Proceedings of the Sixteenth National Academic Conference on Structural Engineering (volume II), 2007. (in Chinese)
[4] Jinqing Jia, Fengshan Chen. Calculate Method and Application on Bridge Engineering Design[M].Beijing: China Architecture \& Building Press, 2003. (in Chinese)

[5] Xiaoguang Zhang, Nannan Han. The Calculation Method for the Lateral Distribution Coefficient of the Bridge at Home and Abroad[J].Gansu Science and Technology, 2011,27 (7): 130-135. (in Chinese)

[6] Qian Jizhang, Shuisheng Chen ,Shiqiang Xu. The Calculation Method of the Transverse Distribution of Beam[J].Engineering Design and Construction, 2005, 37. (in Chinese)

[7] Yijun Ye, Study on the Calculation Method of Transverse Distribution of Multi Cell Box Girder[D]. Chongqing:Chongqing Jiaotong university, 2014. (in Chinese)

[8] Xu Hui. Performance Study and Design Calculation of Box Girder Bridge with Corrugated Steel Webs[D]. Chongqing: Chongqing Jiaotong University, 2006. (in Chinese)

[9] WenWang. Analysis and Model Test of the Torsion and the Distortion Effects of Corrugated Steel Web Box Girders[D]. Changsha: Hunan University, 2008. (in Chinese)

[10] Liming Niu. Study on Geometrical Parameters of PC
Composite Box Girder Bridge Web with Corrugated Steel Webs[D]. Lanzhou: Lanzhou Jiaotong University, 2010. (in Chinese)

[11] Guohao Li and Shi Dong. Calculation of Lateral Distribution of Highway Bridge Load [M]. Beijing: China Communications Press, 1977. (in Chinese)

[12] Qing Liu. Theoretical and Experimental Studies on Transverse Internal Force of Corrugated Steel Web Composite Box Girder[D]. Changsha: Hunan University, 2009. (in Chinese)

[13] Shufen Li. Calculation Analysis and Experimental Research of Transverse Load Distribution of Winged Small Box Girder Bridge[D]. Chengdu: Southwest Jiaotong University, 2007. (in Chinese)

[14] Shuanhai He and Renwu Xie. Calculation Method of Lateral Distribution of Highway Bridge Load [M]. Beijing: China Communications Press, 1996. (in Chinese)

[15] Hua Liu, Jianshu Ye, Bo Yu et al. Calculation Method of Bridge Load Transverse Distribution Coefficient [J]. Journal of Traffic and Transportation Engineering, 2009, 9 (1): 108-116. (in Chinese)

[16] Xie Lan. Analysis of Mechanical Properties of Corrugated Steel Web Box Girder Bridge [D]. Changsha: Central South University of Forestry and Technology, 2013. (in Chinese) 
[17] Wenqing $\mathrm{Wu}$, Jianshu Ye, Shui Wan et al. Study on Shear Lag Effect of Corrugated Steel Web Composite Box Girder under Symmetrical Non-loading [J]. Chinese Journal of Highway, 2003, 16 (2): 68-75. (in Chinese)

[18] Hongjiang Li, Jianshu Ye, Shui Wan et al. Mechanical Properties of Corrugated Steel Web

Box Girder under Unbalance Loading $[\mathrm{J}]$. Journal of Traffic and Transportation Engineering, 2004, 9 (2): 115-122. (in Chinese)

[19] Yue Xu, Wanyong Zhu, Yue Yang. Calculation of Flexural Capacity of Corrugated Steel Web PC Composite Box Girder Bridge $[\mathrm{J}]$. Journal of Chang'an University, 2005, 25 (2): 60-64. (in Chinese)

[20] Xiaoyan Xiao. Carrying Capacity and Fatigue Damage
Analysis of Corrugated Steel Web Composite Box Girder[D]. Changsha: Hunan University, 2009. (in Chinese)

[21] Yu Liao. Study on Several Special Mechanical Properties of Corrugated Steel Web Composite Box Girder[D]. Beijing: Northern Jiaotong University, 2011.(in Chinese)

[22] Fang Wang. Experimental Study on Mechanical Properties of Corrugated Steel Web Composite Box Girder [D]. Changsha: Hunan University, 2007. (in Chinese)

[23] Jihong Yuan. A Study on the Calculation of Transverse Load Distribution of Simply Supported Beam Bridge through Using Half-Wave Sinusoidal Load Instead of Concentration Force[C]. Conference Proceedings of the 16th National Structural Engineering
(Volume II), 2007. (in Chinese)

[24] Jinqing Jia and Fengshan Chen. Bridge Engineering Design Calculation Method and Application[M]. Beijing: China Architecture \& Building Press, 2003. (in Chinese)

[25] Xiaoguang Zhang and Nannan Han. Discussion on Calculation Method of Transverse Distribution Coefficient of Bridge at Home and Abroad[J]. Gansu Science and Technology, 2011, 27 (7): 130-135. (in Chinese)

[26] Jizhang Qian, Shuisheng Chen, Shiqiang Xu. Calculation Method of Transverse Distribution of Simply Supported Beam[J]. Engineering Design and Construction, 2005, 37 (2): 17-22. (in Chinese) 